\title{
Synthesis of pH-Sensitive Hydrogel Based on Starch-Polyacrylate Superabsorbent
}

\author{
Fatemeh Soleimani $^{*}$, Mohammad Sadeghi ${ }^{2}$ \\ ${ }^{1}$ Young Researchers Club, Islamic Azad University, Khorramabad Branch, Khorramabad, Iran; ${ }^{2}$ Department of Chemistry, Science \\ Faculty, Islamic Azad University, Arak Branch, Arak, Iran. \\ Email: *fatisoleymani@yahoo.com
}

Received January $9^{\text {th }}, 2012$; revised February $18^{\text {th }}, 2012$; accepted March $25^{\text {th }}, 2012$

\begin{abstract}
In this article, we synthesize of a novel starch-based superabsorbent hydrogel via graft copolymerization of mixtures of acrylic acid (AA) and 2-Hydroxy ethyl methacrylate (HEMA) onto starch backbones. The polymerization reaction was carried out in an aqueous medium and in the presence of ammonium persulfate (APS) as an initiator and $N, N$ '-methylene bisacrylamide (MBA) as a crosslinker. The hydrogel structures were confirmed by FTIR spectroscopy. Furthermore, the swelling of superabsorbing hydrogels was examined in solutions with $\mathrm{pH}$ values ranging between 1 and 13. It showed a reversible $\mathrm{pH}$-responsive behavior at $\mathrm{pHs} 2$ and 8 . This on-off switching behavior makes the synthesized hydrogels as an excellent candidate for controlled delivery of bioactive agents. A proposed mechanism for hydrogel formation was suggested and the structure of the product was established using FTIR and SEM spectroscopies.
\end{abstract}

Keywords: Starch; Hydrogel; pH-Sensitive; Vinylic Monomers

\section{Introduction}

Loosely crosslinked hydrophilic polymers (hydrogels) being able to absorb and retain hundreds of their own weight of water are known as superabsorbents [1]. The swelling properties of these hydrogels have attracted the attention of researchers and technologists, and have found wide-spread applications in drug delivery systems, agriculture, separation processes and many other fields [2-7].

The modification of natural polymers is a promising method for the preparation of new materials. Graft copolymerization of vinyl monomers onto natural polymers is an efficient approach to achieve these materials. Superabsorbing resins were first developed with a view to utilizing agricultural materials, and are typed by the hydrolyzed corn starch-g-poly(acrylonitrile), H-SPAN [8]. Since then, starches from different resources as well as other polysaccharides, for example, cellulose, hydroxyethyl cellulose [8-13], agar, sodium alginate [3] and guar gum were graft copolymerized to achieve water absorbing polymers. Polyacrylonitrile (PAN), polyacryamide, and poly (acrylic acid) have been frequently grafted, mostly onto starch, using different, initiators especially the ceric-saccharide redox system Radical polymerizetion, however, has several disadvantages. The reproducebility of this method is poor, and there is little control over the grafting process, so the molecular weight distri-

${ }^{*}$ Corresponding author. bution is polydisperse. In addition, the necessity for inert gases (e.g., argon) to prepare an oxygen-free atmosphere and the need for initiators, toxic and/or expensive monomers, and crosslinkers are other disadvantages of freeradical polymerization reactions. These problems have been reviewed in detail. For the first time, Fanta et al., with a new method, tried to synthesize of HSPAN superabsorbent hydrogel. They indicated by a solubility test that crosslinks were formed during graft copolymerizetion, by coupling of the two growing PAN radicals, and during saponification, by the attack of starch alkoxide ions on the nitrile groups as the initioation reaction of nitrile polymerization in the early stages of saponification. The nitrile groups of PAN were converted to a mixture of hydrophilic carboxamide and carboxylate groups during alkaline hydrolysis followed by in situ crosslinking of the grafted PAN chains. The initially formed oxygen-carbon bonds between the starch hydroxyls and nitrile groups of the PAN chains remained crosslinking sites. Then, Fanta and Doane [14] attempted to extend this idea to the preparation of superabsorbent hydrogels by the saponification of PAN in the presence of polyhydroxy polymers. Finally, Yamaguchi et al. [15] reported the preparation of superabsorbing polymers from mixtures of PAN and various saccharides or alcohols.

In this investigation, we paid attention to the synthesis and investigation of a superabsorbent based on starch and 
PAA, PHEMA. The swelling behavior in distilled water in $\mathrm{pH}$ solutions was investigated as well.

\section{Experimental}

\section{Procedure to Graft Copolymerization}

A one step preparative method was used for synthesis of Starch-g-poly(sodiumacrylate-co-HEMA)hydrogel. Starch $(1.33 \mathrm{~g})$ was added to $35 \mathrm{~mL}$ of doubly distilled water in a three-neck reactor equipped with a mechanical stirrer (Heidolph RZR 2021, three blade propeller type).The reactor was immersed in a thermostated water bath preset at a desired temperature $\left(70^{\circ} \mathrm{C}\right)$. Then $0.10 \mathrm{~g}$ of APS as an initiator was added to starch solution and was allowed to stir for $10 \mathrm{~min}$. After adding APS, variable amounts of AA and HEMA were added simultaneously to the starch solution. MBA solution $\left(0.050-0.15 \mathrm{~g}\right.$ in $\left.5 \mathrm{ml} \mathrm{H}_{2} \mathrm{O}\right)$ was added to the reaction mixture after the addition of monomers and the mixture was continuously stirred. After $60 \mathrm{~min}$, the reaction product was allowed to cool to ambient temperature and neutralized to $\mathrm{pH} 8$ by addition of $1 \mathrm{~N}$ sodium hydroxide solution. The hydrogel was poured to excess non solvent ethanol $(200 \mathrm{~mL})$ and remained for $3 \mathrm{~h}$ to dewater. Then ethanol was decanted and the product scissored to small pieces (diameter $\sim 5$ $\mathrm{mm}$ ) [15-20]. Again, $100 \mathrm{~mL}$ fresh ethanol was added and the hydrogel was remained for $24 \mathrm{~h}$. Finally, the filtered hydrogel is dried in oven at $60^{\circ} \mathrm{C}$ for $10 \mathrm{~h}$. After grinding, the powdered superabsorbent was stored away from moisture, heat and light. Infrared spectroscopy (Figure 1) and SEM (Figure 2) were carried out to confirm the chemical structure of the materials obtained. Crosslinking graft copolymerization of vinyl monomers (AA and HEMA) onto starch was shown in Scheme 1.

\section{Results and Discussion}

\subsection{Effect of pH on Equilibrium Swelling}

In this series of experiments, swelling ratio for the synthesized hydrogels was measured in different $\mathrm{pH}$ solu-

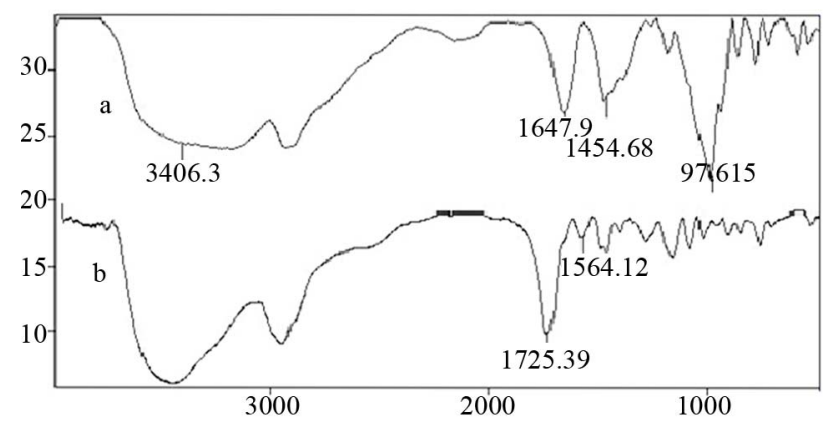

Transmittance/Wavenumber $\left(\mathrm{cm}^{-1}\right)$

Figure 1. FTIR spectra of (a) the pure Starch and (b) the crosslinked Starch-poly(NaAA-co-HEMA) hydrogel.
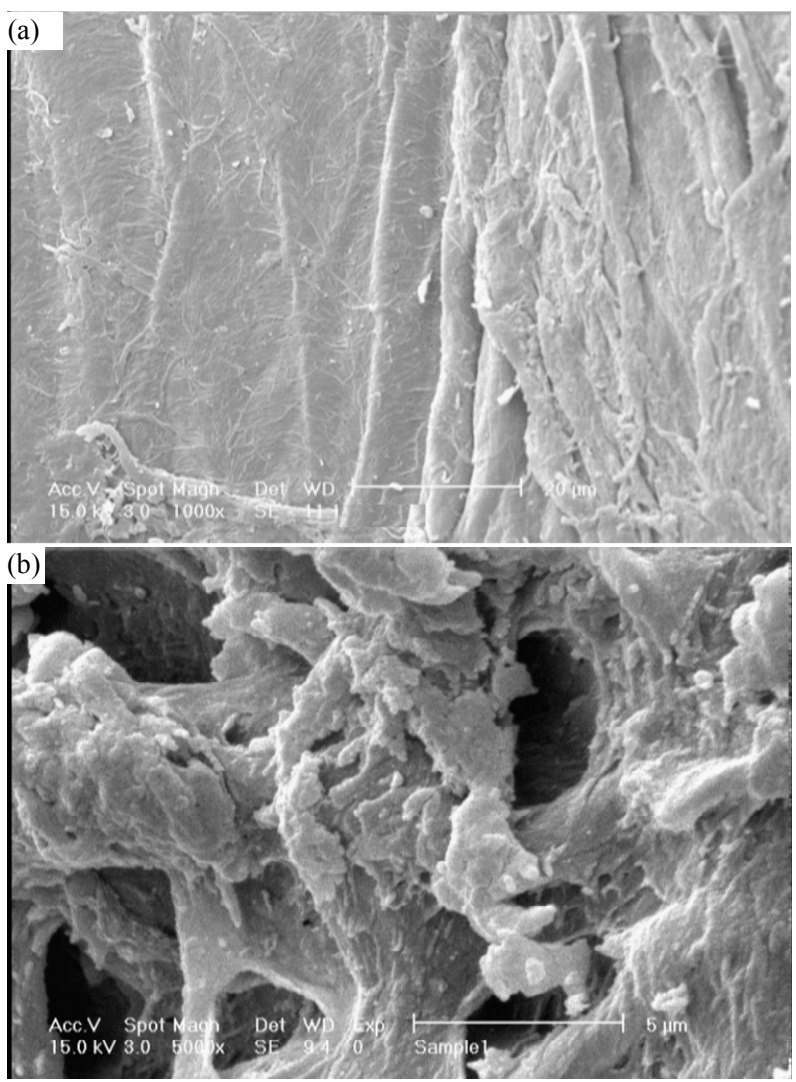

Figure 2. SEM photograph of the optimized superabsorbent hydrogel (a) Surface of pure carboxymethylcelloluse; (b) Surface of porous hydrogel.

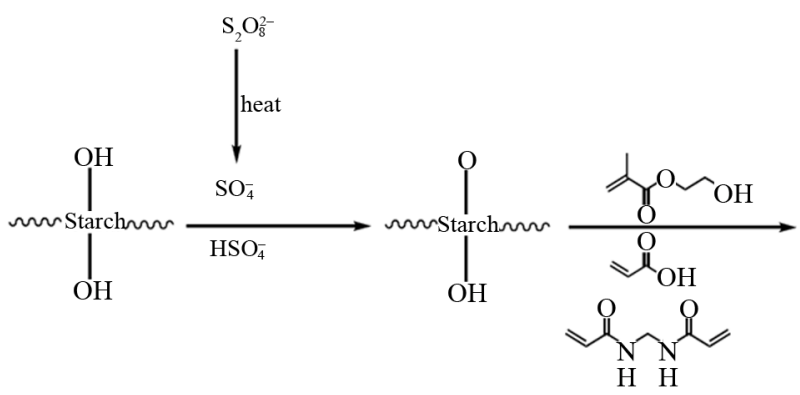

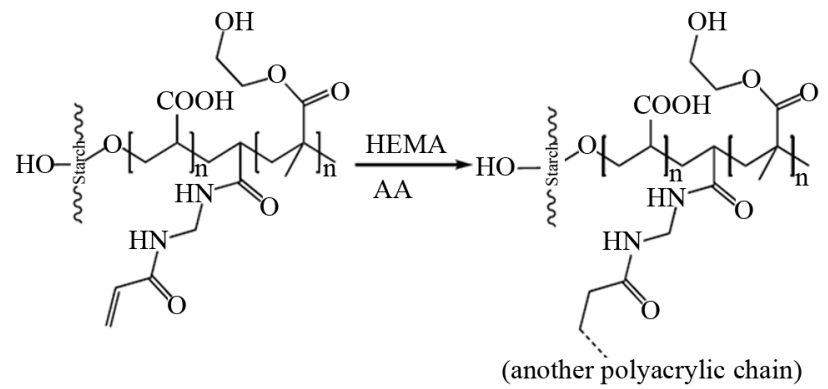

Scheme 1. A proposed mechanism for synthesis of Starchpoly(NaAA-co-HEMA) hydrogel. 


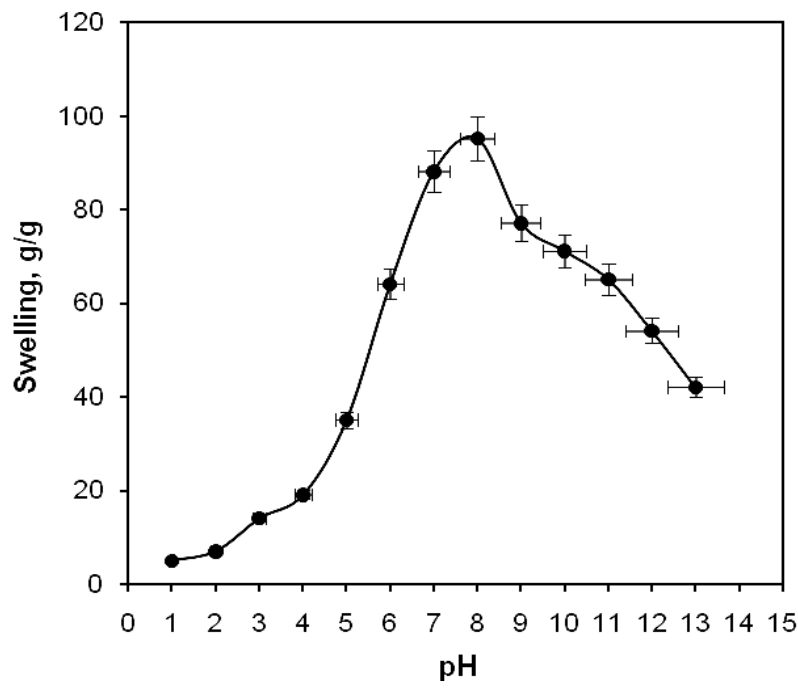

Figure 3. pH-dependent swelling of the superabsorbent hydrogel.

tions ranged from 1.0 to 13.0 (Figure 3). Since the swelling capacity of all "anionic" hydrogels is appreciably decreased by the addition of counter ions (cations) to the swelling medium, no buffer solutions were used. Therefore, stock $\mathrm{NaOH}(\mathrm{pH} 10.0)$ and $\mathrm{HCl}(\mathrm{pH} 1.0)$ solutions were diluted with distilled water to reach desired basic and acidic pHs, respectively. Maximum swelling $(95 \mathrm{~g} / \mathrm{g})$ was obtained at $\mathrm{pH}$ 8. In acidic media, most carboxylic acid groups are protonated, so decreased repulsion of anionic groups leads to a decreased swelling ratio. At higher pHs (5 - 8), some carboxylate groups are ionized and the electrostatic repulsion between carboxylate groups causes an enhancement of the swelling capacity. The reason of the swelling loss for the highly basic solutions is the charge screening effect of excess $\mathrm{Na}^{+}$ in the swelling media, which shield the carboxylate anions and prevent effective anion-anion repulsion. Similar swelling-pH dependencies have been reported in the case of other hydrogel systems [21-25].

\section{2. pH-Responsiveness Behavior of the Hydrogel}

Since the semi-IPN hydrogels show different swelling behaviors at various $\mathrm{pHs}$, so we investigated their $\mathrm{pH}-\mathrm{re}-$ versibility in the solutions buffered at $\mathrm{pHs} 2$ and 8 (Figure 4). The figure shows a stepwise reproducible swelling change of the hydrogel at $25^{\circ} \mathrm{C}$ with alternating $\mathrm{pH}$ between 2 and 8. At pH 8.0, the hydrogel swells up to 95 $\mathrm{g} / \mathrm{g}$ due to anion-anion repulsive electrostatic forces, while, at $\mathrm{pH} 2.0$, it shrinks within a few minutes due to protonation of solfunate groups. This sharp swelling-deswelling behavior of the hydrogels makes them suitable candidates for controlled releasing systems. Such on-off switching behavior as reversible swelling and deswelling

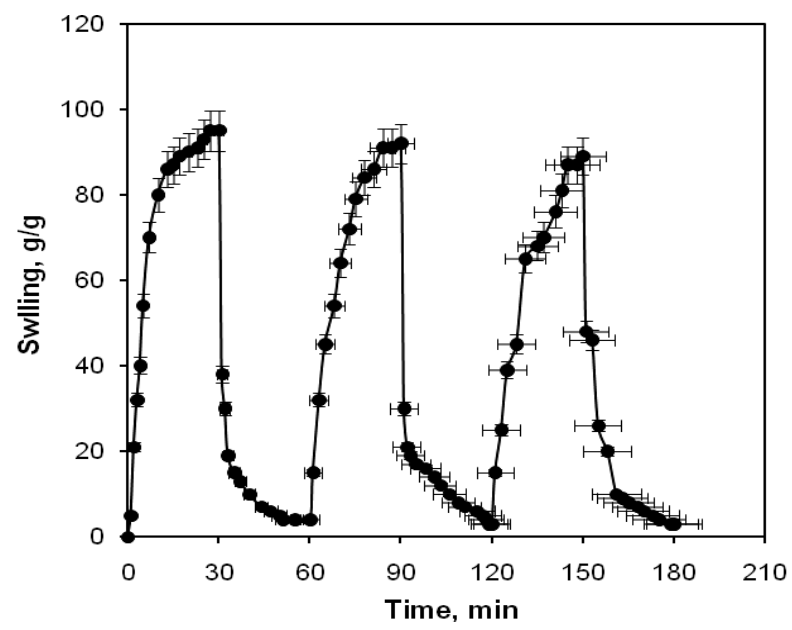

Figure 4. The pH-responsiveness behavior of starch-g-poly (AA-co-HEMA) superabsorbing hydrogel in solutions with pH 2.0 and 8.0.

has been reported for other ionic hydrogels [26-30].

\section{Conclusion}

The superabsorbent hydrogel, starch-g - poly(NaAA-coHEMA), was synthesized through graft copolymerization mixture. The maximum water absorbency superabsorbent in solutions with $\mathrm{pH}=8$ was $95 \mathrm{~g} / \mathrm{g}$. Also the superabsorbent hydrogels exhibited high sensitivity to $\mathrm{pH}$, so that, several swelling changes of the hydrogel or drug releaseing percent were observed in lieu of $\mathrm{pH}$ variations in a wide range (1-13). Furthermore, the reversible swellingdeswelling behavior in solutions with acidic and basic $\mathrm{pH}$, makes the hydrogels as a suitable candidate for controlled releasing systems.

\section{Acknowledgements}

The authors thank the Research center of Islamic Azad University of Arak.

\section{REFERENCES}

[1] D. C. Hwang, S. Damodaran, "Synthesis and Properties of Fish Protein-Based Hydrogel," Journal of the American Oil Chemists' Society, Vol. 74, No. 9, 1997, pp. 1165-1171.

[2] J. Kost, "Encyclopedia of Controlled Drug Delivery," Vol. 1, Wiley, New York, 1999, p. 445.

[3] A. S. Hoffman, "Polymeric Materials Encyclopedia," Vol. 5, CRC Press, Boca Raton, 1996, p. 3282.

[4] N. A. Peppas, A. G. Mikes, "Hydrogels in Medicine and Pharmacy," Vol. 1, CRC Press, Boca Raton, 1986.

[5] D. W. Jenkins, S. M. Hudson, "Review of Vinyl Graft Copolymerization Featuring Recent Advances toward Controlled Radical-Based Reactions and Illustrated with Chitin/Chitosan Trunk Polymers," Chemical Reviews, 
Vol. 101, No. 11, 2001, pp. 3245-3273. doi:10.1021/cr000257f

[6] N. Miyata, M. Yokoyama, I. Sakata, "Properties of Highly Water-Absorptive Hydroxyethylcellulose Graft Copolymers: Viscoelasticity and Moisture Sorption," Journal of Applied Polymer Science, Vol. 55, No. 2, 1995, pp. 201-208. doi:10.1002/app.1995.070550202

[7] E. Rezai and R. R. Warner, "Polymer-Grafted Cellulose Fibers. I. Enhanced Water Absorbency and Tensile Strength," Journal of Applied Polymer Science, Vol. 65, No. 8, 1997, pp. 1463-1469. doi:10.1002/(SICI)1097-4628(19970822)65:8<1463::AID -APP3>3.0.CO;2-E

[8] Y.-J. Kim, K. J. Yoon and S. W. Ko, "Preparation and Properties of Alginate Superabsorbent Filament Fibers Crosslinked with Glutaraldehyde," Journal of Applied Polymer Science, Vol. 78, No. 10, 2000, pp. 1797-1804. doi:10.1002/1097-4628(20001205)78:10<1797::AID-AP P110>3.0.CO;2-M

[9] J. C. Salamone, E. L. Rodriguez, K. C. Lin, L. Quach, A. C. Watterson and I. Ahmad, "Aqueous Salt Absorption by Ampholytic Polysaccharides," Polymer, Vol. 26, No. 8, 1985, pp. 1234-1238. doi:10.1016/0032-3861(85)90259-9

[10] G. F. Fanta, "Polymeric Materials Encyclopedia," Vol. 10, CRC Press, Boca Raton, 1996, p. 7901, 8051.

[11] Y. Zhu, B. Pu, J. Zhang and J. Shen, "Synthesis of AntiSalt Absorbent Resins and Studies of Reaction Mechanism," Journal of Applied Polymer Science, Vol. 79, No. 3, 2001, pp. 572-574. doi:10.1002/1097-4628(20010118)79:3<572::AID-APP2 10>3.0.CO;2-T

[12] H. T. Lokhande, P. V. Varadarajan and V. Iyer, "WaterSuperabsorbent Polymers through Gamma RadiationInduced Graft-Copolymerization of Acrylonitrile on Guargum," Journal of Applied Polymer Science, Vol. 45, No. 11, 1992, pp. 2031-2036. doi:10.1002/app.1992.070451117

[13] V. D. Athawale and V. L. Lele, "Recent Trends in Hydrogels Based on Starchgraft-Acrylic Acid: A Review," Starch/Starke, Vol. 53, No. 1, 2001, pp. 7-13. doi:10.1002/1521-379X(200101)53:1<7::AID-STAR7>3. 0.CO;2-Q

[14] D. W. Lim, H. S. Whang and K. J. Yoon, "Synthesis and Absorbency of a Superabsorbent from Sodium Starch Sulfate-g-Polyacrylonitrile," Journal of Applied Polymer Science, Vol. 79, No. 8, 2001, pp. 1423-1430. doi:10.1002/1097-4628(20010222)79:8<1423::AID-APP 90>3.0.CO;2-V

[15] R. M. Silverstein, F. X. Webster, "Spectrometric Identification of Organic Compounds," 6th edition, Wiley, New York, 1998.

[16] M. O. Weaver, L. A. Gugliemeli, W. M. Doane and C. R. Russel, "Hydrolyzed Starch-Polyacrylonitrile Graft Copolymers: Effect of Structure on Properties," Journal of Applied Polymer Science, Vol. 15, No. 12, 1971, pp. 3015-3024. doi:10.1002/app.1971.070151211

[17] E. Sjostrom, "Fundamental of Carbohydrate Chemistry and Wood Chemistry: Fundamentals and Applications," Academic, San Diego, 1981.

[18] P. J. Flory, "Principles of Polymer Chemistry," Cornell University Press, Ithaca, New York, 1953.

[19] D. Castel, A. Ricard and R. Audebert, "Swelling of Anionic and Cationic Starch-Based Superabsorbents in Water and Saline Solution," Journal of Applied Polymer Science, Vol. 39, No. 1, 1990, pp. 11-29. doi:10.1002/app.1990.070390102

[20] G. R. Mahdavinia, A. Pourjavadi and M. J. Zohuriaan-Mehr, "Modified Chitosan III, Superabsorbency, Salt- and pH-sensitivity of Smart Ampholytic Hydrogels from Chitosan-g-PAN," Polymers for Advanced Technologies, Vol. 15, No. 4, 2004, pp. 173-180. doi: $10.1002 /$ pat. 408

[21] J. J. Hermans, "Flow Properties of Disperse Systems," Wiley Interscience, New York, 1953.

[22] W. F. Lee and W. Y. Yuan, "Thermoreversible Hydrogels $\mathrm{X}$ : Synthesis and Swelling Behavior of the (N-isopropylacrylamide-co-sodium 2-acrylamido-2-methylpropyl sulfonate) Copolymeric Hydrogels," Journal of Applied Polymer Science, Vol. 77, No. 8, 2000, pp. 1760-1768. doi:10.1002/1097-4628(20000822)77:8<1760::AID-APP $13>3.0 . \mathrm{CO} ; 2-\mathrm{J}$

[23] S. E. Park, Y. C. Nho, Y. M. Lim and H. Kim, "Preparation of $\mathrm{pH}$-Sensitive Poly(vinyl alcohol-g-methacrylic acid) and Poly(vinyl alcohol-g-acrylic acid) Hydrogels by Gamma Ray Irradiation and Their Insulin Release Behavior," Journal of Applied Polymer Science, Vol. 91, No. 1, 2004, pp. 636-643. doi:10.1002/app.13211

[24] K. Burugapalli, D. Bhatia, V. Koul and V. Choudhary, "Interpenetrating Polymer Networks Based on Poly (acrylic acid) and Gelatin. I: Swelling and Thermal Behavior," Journal of Applied Polymer Science, Vol. 82, No. 1, 2001, pp. 217-227. doi:10.1002/app.1841

[25] S. Lu, M. Duan and S. Lin, "Superabsorbent Polymeric Materials VIII: Swelling Behavior of Crosslinked Poly [sodium acrylate-co-trimethyl methacryloyloxyethyl ammonium iodide] in Aqueous Salt Solutions," Journal of Applied Polymer Science, Vol. 79, No. 9, 2001, pp. 1665-1674.

doi:10.1002/1097-4628(20010228)79:9<1665::AID-APP 160>3.0.CO;2-P

[26] A. Pourjavadi, M. Sadeghi and H. Hosseinzadeh, "Modified Carrageenan. 5. Preparation, Swelling Behavior, Saltand $\mathrm{pH}$-Sensitivity of Partially Hydrolyzed Crosslinked Carrageenan-graft-polymethacrylamide Superabsorbent Hydrogel," Polymers for Advanced Technologies, Vol. 15, No. 11, 2004, pp. 645-653. doi:10.1002/pat.524

[27] A. M. Lowman and N. A. Peppas, "Encyclopedia of Controlled Drug Delivery,” Wiley, New York, 1999, p. 139.

[28] A. Richter, A. Bund, M. Keller and K. Arndt, "Characterization of a Microgravimetric Sensor Based on $\mathrm{pH}$ Sensitive Hydrogels," Sensors and Actuators B: Chemical, Vol. 99, No. 2-3, 2004, pp. 579-585. doi:10.1016/j.snb.2004.01.011

[29] L. H. Gan, G. R. Deen, Y. Y. Gan and K. C. Tam, "Water Sorption Studies of New pH-Responsive N-acryloyl-N'- 
methyl piperazine and Methyl Methacrylate Hydrogels," European Polymer Journal, Vol. 37, No. 7, 2001, pp. 1473-1478. doi:10.1016/S0014-3057(00)00250-0

[30] F. L. Buchholz, "Superabsorbent Polymers: Science and
Technology," In: F. L. Buchholz and N. A. Peppas, Eds., ACS Symposium Series 573, American Chemical Society, Washington DC, 1994. 